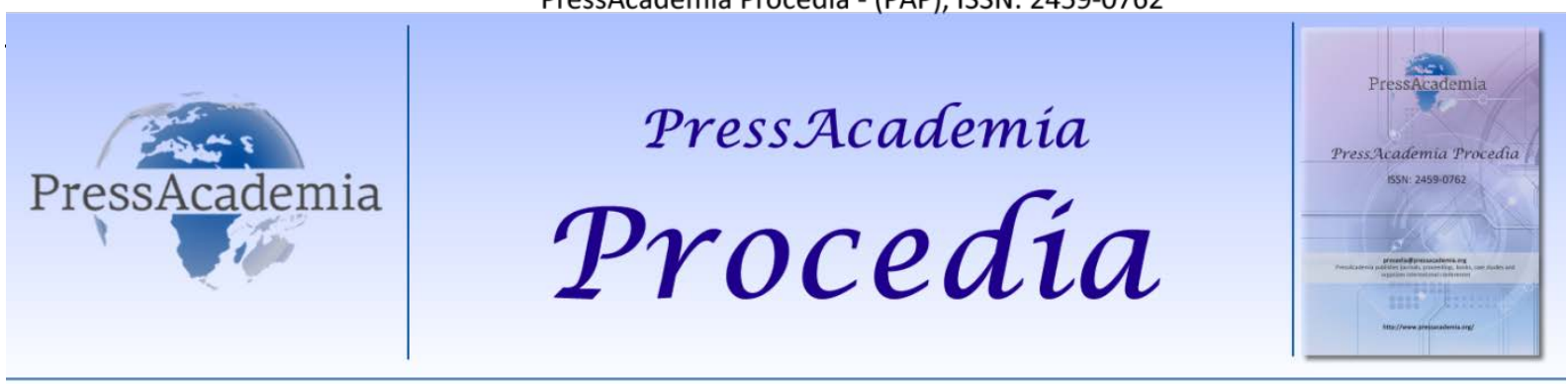

Global Business Research Congress (GBRC), May 26-27, 2016, Istanbul, Turkey.

\title{
DYNAMIC QUALITY MANAGEMENT APPROACH FOR LEAN MANAGEMENT SYSTEMS: A FUTURE PERSPECTIVE FOR COMPANIES?
}

\section{DOI: 10.17261/Pressacademia.2016118666}

\author{
M. Sahin Gok $^{1}$, Tugkan Arici ${ }^{2}$ \\ ${ }^{1}$ Gebze Technical University, sahingok@gtu.edu.tr \\ ${ }^{2}$ Gebze Technical University, tarici@gtu.edu.tr
}

\begin{abstract}
In today's highly competitive and rapidly changing business environment, the issues of efficiency and productivity are essential concerns for all industries. Dynamic quality management has emerged as an innovation model that integrates systematic process concerns into business processes. Considering the lean management system philosophy, which mainly aims to eliminate waste by using effective tools, integrated dynamic quality management has become a key factor for increasing effectiveness. Accordingly, this study mainly aims to examine the relationship between dynamic quality management and lean production systems through the whole business processes. This ambiguous relationship is theoretically analyzed by using recent studies in the management field as a meta-analysis method. The study findings demonstrate how to build the necessary business model for achieving success in dynamic quality management approach. Consequently, the insightful comments are provided for both academic researchers and sectoral managers.
\end{abstract}

Keywords : Dynamic quality management, lean management, meta-analysis method

JEL Codes: L21, M10, M19

\section{YALIN YÖNETIM SISTEMLERi içiN DINAMIK KALITE YÖNETIMI YAKLAŞIMI: ŞiRKETLER içiN GELECEK PERSPEKTIFI?}

\section{ÖZET}

Günümüzün rekabetçi ve hızla değişen işletme çevresinde, etkinlik ve verimlilik tüm sektörler için öncelikli konuların başında gelmektedir. Dinamik kalite yönetim sistemi, işletme süreçlerini sistematik yaklaşımla entegre etmesi bakımından yenilikçi bir model ortaya koymaktadır. Katma değer sağlamayan faaliyetlerin elimine edilme temel felsefesine sahip yalın yönetim sistemi ile entegre edilmiş dinamik kalite yönetim sistemi etkinliği arttırmak için anahtar bir rolde değerlendirilebilir. Bu anlamda bu çalışma kapsamında dinamik kalite yönetim sistemi ile yalın üretim sistemi ilişkisi meta-analizi yöntemi kullanılarak teorik olarak analiz edilmiştir. Çalışma bulgularının dinamik kalite yönetimi sisteminden başarı sağlamak için gerekli işletme modelini ortaya koyması bakımından önem taşımaktadır. Bu anlamda gerek akademik araştırmacılara gerekse de sektörel yöneticilere ışık tutacak sonuçlar ortaya konabilmektedir.

Anahtar Kelimeler: Dinamik kalite yönetimi, yalın yönetim, meta-analiz metodu JEL Kodları: L21, M10, M19 


\section{GíRiş}

Dünyamızda gün geçtikçe rekabet artmakta ve küreselleşmeyle birlikte müşterilerin istek ve memnuniyetini sağlamak, sadık bir müşteri portföyü yaratmak neredeyse imkansız hale geldi. Ancak sadık bir müşterinin önemi de yadsınamaz bir gerçektir. Hem sadık müşteri yaratmak hem de müşterilerimizin istek ve ihtiyaçlarını en az maliyetle hayata geçirmek için süreçlerimizde sürekli bir iyileştirmeye gitmemiz gerekmektedir.

Günümüzde yaşanan sert rekabet nedeniyle işletmeler; ürünlerini hızlı tedarik etmeyi, müşteri istek ve ihtiyaçlarına daha seri bir şekilde cevap vermeyi ve tüm bu işlemleri de minimum maliyet ile gerçekleştirmeyi amaçlamaktadır. Çünkü her an gelişim gösteren teknoloji nedeniyle daha fazla talepkar olmuş müşteriler, daha fazla özelliğe sahip ürünleri almayı arzulamaktadırlar.

İşletmelerde tıpkı insanlar gibi birer canlı varlıklardır ve tıpkı diğer tüm canlı varlıklar gibi doğarlar, gelişirler ve eğer gelişmelere ayak uyduramazlarsa da bir gün ölürler. Bu gelişme istekleri kimi zaman firma içerisinden çıkabileceği gibi kimi zamanda dış kaynaklı zorlamalarla gerçekleşebilir. İşletmeler bu değişimlere direnmeden, kendisi için en uygun olan değişimi hızlıca süreçlerine entegre etmelidir. Süreçleri sürekli kontrol etmek, iyileştirmek ve değişimlere ayak uydurmak firmalara; müşteri memnuniyeti, maliyet avantajı, kalite ve performanslarda artış olarak geri dönmektedir (Çankır, 2010).

Çalışmanın bulguları arasında, dinamik kalite yönetimi yaklaşımının başarılı olabilmesi için gerekli olan bir iş modelinin nası inşa edilmesi gerektiğini gösteren bir önerinin ortaya çıkartılması hedeflenmiştir. Analiz sonuçları kurumsal temelleri belirleyecek ve aynı zamanda dinamik kalite yönetimi ve yalın yönetim yaklaşımları gibi yönetim altında yatan bileşenler arasındaki sinerjik ilişkiyi açıklamaya yardım edecektir.

\section{LITERATÜR TARAMASI}

İşletme içerisindeki süreci; “makine, malzeme, para, bilgi ve zaman gibi kaynakları alıp işleyen ve onlara değer katarak müşteri istek ve beklentilerine uygun çıktılar meydana getirmek" olarak tanımlayabiliriz (Gaga, 2009). İyi bir süreç için işletmeler:

- Müşteri odaklı olmalıdır,

- $\quad$ Girdiye değer katmalıdır,

- Sorumlular belli olmalıdır,

- $\quad$ Sürekli iyileştirme geçirmelidir (Gaga, 2009).

Müşteri odaklılık, doğru müşteriye, doğru zamanda, doğru fiyat ile doğru ürün veya hizmetin sunulması demektir . Toplam Kalite Yönetimi (TKY)'nin de en temel ilkesi müşteri odaklılıktır. TKY'nin buradaki amacı; müşteri ihtiyaçlarını en iyi şekilde giderecek hatta müşteri beklentilerinin üstünde bir ürün veya hizmet kalitesi sağlamaktır. Firmalar müşterilerin şimdiki ve gelecekteki beklentilerini tespit etmeli ve müşteri istek ve ihtiyaçlarını tam olarak karşılamayı amaçlamalıdır. Bu anlamda süreçleri sürekli kontrol etme ve iyileştirme, işletmeler için kaçınılmaz bir gerekliliktir (Çakır, 2007).

Toplam Kalite Yönetimi'nin kurucularından Deming'in yaptığı tanıma göre: “insanlar belirli bir sistem içerisinde çalışırlar. Bu sistemde yöneticilerin görevi, tüm çalışanların katılımı ve desteği ile sistemi sürekli iyileştirmektir" Bu tanımdan da anlaşılacağı üzere, süreçleri sürekli iyileştirme TKY'nin ana felsefesidir ve yalın düşüncenin de temel taşlarından biridir (Çakır, 2007).

Yalın üretim felsefesinin de temelinde yine israfı azaltmak, sıfır hata ve sıfır maliyet düşüncesi yatmaktadır. Yalın üretim felsefesi dikey örgütlenmenin aksine yatay örgütlenmeyi amaçlamaktadır. Yalın üretim felsefesinin temelinde; organizasyon yapısını basitleştirme, gereksiz ve değer katmayan her adımı iş sürecinden atma ve bu sayede daha iyi ve kaliteli ürünü müşteri isteğine sunma yatar (Şenel, 2004).

TKY sadece sıfır hata ile üretim yapmayı değil aynı zamanda mükemmel bir iş sistemi kurmayı da amaçlamaktadır. Mükemmel bir sistemi kurmak için işletmenin tüm birimleri ortak özveri ve katılım ile işlemlerini yerine getirmelidir. Bu anlamda da, işletmeler için TKY ve süreç iyileştirme aslında birbirinden ayrılmaz iki parçadır (Şenel, 2004). 
Yalın düşüncenin temeli de aslında yalın üretim felsefesinden pekte farklı değildir. Yalın düşüncenin temel amacl; tedarikçinin tedarikçisinden başlayan ve nihai tüketiciye sunmak ile sonlanan üretim zincirinin tüm süreçlerinde, hiçbir kesintiye uğramadan, en az israfla ve en hızlı şekilde ürün veya hizmeti müşteriye sunmaktır. Bunu başarılı bir şekilde gerçekleştirmek içinde tüm sürece bir bütün halinde bakılmalıdır. Klasik TKY mantığııın aksine TKY kontrolleri modüler bazda değil tüm sürece entegre bir şekilde olmalıdır. Böylece hem tüm süreç boyunca hem de tüm faaliyet zincirimiz içerisinde mükemmele en yakın değer oluşturulabilecektir (Çankır, 2010).

Dinamik Kalite Yönetimi tam da bu noktada, tüm değer zincirinin sistematik süreç kaygılarını iş süreçlerine entegre eden bir yenilikçi model olarak karşımıza çıkmaktadır. Yalın yönetim felsefesinin temel amacı olan, sistemdeki israfları sürekli azaltma ve kaynaklardan daha fazla değer yaratma düşüncesi, kullanılan etkili araçlar vasıtasıyla gerçekleşmektedir. Yalın yönetim felsefesi ile dinamik kalite yönetimini entegre etmek, israfların azaltılması adına bir anahtar faktör olduğu son zamanlarda yapılan araştırmalarla ortaya çıkmıştır.

\section{VERI VE YÖNTEM}

Biz bu çalışmamızda; değer zincirinin tüm işlem süreçleri boyunca, dinamik kalite yönetimi ve yalın üretim sistemleri arasındaki ilişkiyi inceleyeceğiz. Şu an için belirsiz olan bu ilişkiyi, aynı konu üzerinde birbirinden bağımsı olarak yapılmıs deney ve çalışmalardan elde edilen sonuçları bir araya getirerek; bu sonuçlardaki çeşitliliği açıklamak, daha güvenilir ve doğru sonuçlar elde etmek için geliştirilen Meta analiz metodunu kullanarak teorik olarak analiz etmeyi amaçlamaktayız (Çarkungöz ve Ediz, 2009).

\section{BULGULAR VE TARTIŞMA}

Bölgesel üretimin yerini zamanla küresel üretimin almasıyla birlikte işletmeler için rekabet daha da zorlaşmıştır. İşletmeler artık sadece kendi bölgelerinde üretim yapan işletmelerle değil küresel bir güç haline gelmiş işletmelerle de rekabet etmek zorunda kalmıştır. Bu zor şartlar içerisindeki işletmeler, faaliyetlerini devam ettirebilmek için maliyetlerini en aza indirgeyerek müşteri beklentilerine en yakın hatta müşteri beklentilerinin üstündeki ürünleri piyasaya sunmaları gerektiğini fark etmişlerdir.

İşletmeler için darboğaz oluşturan bu gelişmeler neticesinde firmalar; müşteri talebine uygun, yenilikçi, daha az maliyetli, daha kaliteli ve rakiplerinden farkı ürün veya hizmeti sunmak için çeşitli üretim teknikleri denemiştir (Özçelik, 2013). Son yirmi yıl içerisinde çoğu işletme tam zamanında, kısıtlar teorisi, altı sigma, değer akış yönetimi ve hedef maliyetleme gibi kavramları içerisinde barındıran yalın üretim tekniklerini uygulamaya başlamıştır (Ertürk ve Özçelik, 2008).

1950'li yıllarda ilk defa Toyota fabrikasında denenen yalın üretim tekniğinin yaklaşık 60 yıllık bir geçmişi bulunmaktadır (Aziz \& Hafez, 2013). Yalın üretim sistematiği ile süreçlerini organize eden işletmeler; en az kaynakla, en az maliyetle, en az insan emeğiyle, en az süreyle, bol çeşitli ve en kaliteli ürünü en uygun fiyatla müşterilerine sunabilmektedir (Ertürk ve Özçelik, 2008).

John Krafcik yalın üretimi “(...) yapısında hiç bir gereksiz unsuru taşımayan ve hata, maliyet, stok, işçilik, geliştirme süreci, üretim alanı, fire ve müşteri memnuniyetsizliği gibi unsurların en aza indirgendiği bir üretim sistemi (...)"olarak tanımlamıştır (Aydın, 2009). Yalın üretim felsefesi sadece maliyet azaltma ve israfları yok etme felsefesi değildir. Yalın üretim felsefesi, maliyet azaltma ilkesini uygularken Toplam Kalite Yönetimi (TKY)'nin de inşa edilmesini hedeflemektedir (Amasaka, 2002).

Yalın üretim tekniğinin dünyada uygulayan pek çok küresel firma bulunmaktadır. Yalın üretim tekniklerini kullnarak; Toyota, Nissan, General Motors gibi işletmeler de \%50 oranında çalışma sürelerinde azalma, \%30 oranında üretim alanı kazandırma, \%80 oranında maliyet ve verimlilik artışı sağlamıştır (Nguyen, 2015).

Bilgi ve süreçlerin sürekli iyileştirilmesi ve yenilenmesi kaçınılmaz bir gerçektir (Güler, 2010). Teknolojinin artmasıyla pazara yeni ürünler sunulacak, sunulan her yeni üründen sonra müşteri beklenti ve istekleri daha da artacak, artan beklenti ve isteklerde tekrardan yeni birer ürün veya hizmetin üretilmesini zorunlu tutacaktır. Değişmeyen tek şey değişimin kendisidir sözü bu bağlamda süreç yönetiminin ana felsefesini de oluşturmaktadır. 
Pazardaki işletmeler, herkes için eşit olan bu ortamda rakiplerine karşı rekabet avantajı elde etmek ve pazar paylarını korumak ya da pazar paylarını arttırmak için Porter'ın jenerik (Bordean, et.al., 2011) stratejiler olarak tanımlamıs olduğu üç temel stratejiden bir veya bir kaçını seçebilirler. Farklılaştırma, Maliyet Avantajı ve Cevap Verebilme stratejilerinden hangisi seçilirse seçilsin, işletmeler tarafından atılacak ilk adım süreçlerini incelemek, belirlemek ve iyileştirmek olmalıdır.

Türk Dil Kurumu'na göre süreç; “Aralarında birlik olan veya belli bir düzen veya zaman içinde tekrarlanan, ilerleyen, gelişen olay ve hareketler dizisi" olarak tanımlanmaktadır.(TDK, 2016). Süreç planlaması, istenilen ürün ya da hizmetin istenilen miktarda, en uygun maliyetle üretilmesini sağlayacak üretim sisteminin tasarlanması ve uygulanması faaliyetlerini kapsamaktadır (Doğan ve Takcı, 2015). Süreç yönetimi ise, işletmenin süreçlerini iyileştirebilmek için tüm süreçlerin belirlenmesini, tanımlanmasını, süreçler için performans ölçütünün konmasını ve süreçleri sürekli kontrol etmektir (Yılmazer ve Sarıaltın, 2011).

Süreç yönetimi ya da diğer adıyla iş süreçleri yönetimi, işletme genelinde verimlilik ve iş süreçlerinin etkinliğini artırmak için kapsamlı bir yönetim yaklaşımıdır (Zheltonogov, et.al, 2015). Süreç yönetimi son yıllarda çok fazla önem kazandı ve pek çok işletme bugün kendi iş süreçlerini görmek ve süreçlerini iyileştirmek için anahtar performans göstergelerini belirlemektedir (Brocke, Zelt \& Schmiedel, 2016). Çünkü son yıllarda yapılan çeşitli araştırmalar, süreç yönetimi ve iş başarısı arasında pozitif bir korelasyon olduğunu göstermektedir (Trkman, 2010).

Süreç yönetiminin işletme içerisindeki üretim, pazarlama, iletişim ve diğer ana işlemleri tanımlamak, bu temel faaliyetleri analiz etmek ve geliştirmek gibi amaçları vardır (Trkman, 2010). Bu anlamda süreç yönetimi, süreçlerin verimliliğini ve etkinliğini arttırmaya odaklanmakla kalmamış, işletmelere yeni fırsatlarda sunmuştur (Brocke, Zelt \& Schmiedel, 2016).

\section{SONUÇ}

Süreç yönetimi ile işletmeler; maliyetlerini minimum seviyeye çekmek, kar maksimizasyonu sağlamak ve müşteri memnuniyetini sağlayabilmek için üretim veya hizmetleri esnasında süreçlerini irdelemeli ve sürece katkıda bulunmayan adımlarını çıkartmalıdır. Süreçleri incelemek işletmelere; katkıda bulunmayan adımları görme, hatalı ürün sebeplerini hemen fark edebilme ve süreçlerini iyileştirme fırsatı sunduğu gibi müşteri isteklerine uyum sağlamada da katkı sağlayacaktır.

Süreç odaklı olmak aslında kalite kontrol yapmak yerine kaliteyi yaratmak demektir (İnce, Erol ve Karagöz, 2013). Klasik yönetim anlayışında ürünler üretildikten sonra ürünler kontrol edilir. Hatalar üretim bittikten sonra fark edileceğinden boşa zaman ve enerji harcanmasının yanı sıra maliyetleri de arttırmaktadır. Oysaki süreçler kontrol altına alınırsa ve her bir adım kontrolden geçirilirse hatalar hemen fark edilebilir ve zaman, enerji ve emek israflarından kaçınılır (ince, Erol ve Karagöz, 2013).

Bu anlamda temelini süreç yönetiminden alan dinamik kalite yönetim sistemi ile entegre edilmiş olan yalın yönetim felsefesi işletmelerin faaliyetlerini daha etkin, kontrol edilebilir ve sürdürülebilir bir yapıya kavuşturma potansiyelini taşımaktadır. İşletmeler açısından etkin bir dinamik kalite yönetim sistemi kurmanın öncelikli yapı taşı işletme faaliyetlerini süreç mantığı ile tanımlarken, katma değer yaratma potansiyellerini belirlemek ve bu şekilde atıl kapasiteyi minimize ederek verimliliği, kontrol edilebilir yapıyı ve makro boyutta sürdürülebilirliği sağlamaktan geçmektedir.

\section{KAYNAKLAR}

Amasaka, K. 2002, “New JIT: A New Management Technology Principle At Toyota”, International Journal Production Economics, vol. 80, pp. $135-144$.

Aydın, H. 2009, "Yalın Üretim Sistemi, Değer Akış Haritalama Yöntemi ve Yalın Üretim Sisteminin Çalışanlara Etkileri", Yüksek Lisans Tezi, Sosyal Bilimler Enstitüsü, Marmara Üniversitesi, İstanbul.

Aziz, R.F. \& Hafez, S.M. 2013, "Applying lean thinking in construction and performance improvement", Alexandria Engineering Journal, vol. 52, pp. 679-695. 
Bordean, O.N., Borza, A. \& Glaser-Segura, D. 2011, "A Comparative Approach of the Generics Strategies Within The Hotel Industry: Romania VS. USA", Management \& Marketing Challenges fort he Knowledge Society, vol. 6, no. 4, pp. 501-5014.

Brocke, J.V., Zelt, S. \& Schmiedel, T. 2016, “On The Role of Context In Business Process Management", International Journal of Information Management, vol. 36, pp. 486-495.

Çakır, A. 2007, “Hasta Güvenliği Kültürü İle Kalite Yönetim Sistemi Arasındaki İlişkinin Analizi”, Yayımlanmış Yüksek Lisans, Dokuz Eylül Üniversitesi, Sosyal Bilimler Enstitüsü, İzmir.

Çankır, B. 2010, "Yalın Düşünce Sistemini Uygulayan Kurumlarla Uygulamayan Kurumlarda Çalışanlarda Örgütsel Vatandaşlık Davranışı", Yayımlanmış Yüksek Lisans Tezi, Marmara Üniversitesi, Sosyal Bilimler Enstitüsü, İstanbul.

Çarkungöz, E. \& Ediz, B. 2009, “Meta Analizi”, Uludag University Journal Of The Faculty Of Veterinary Medicine, vol. 28, no. 1, pp. 33-35.

Doğan, N.Ö. \& Takcı, E. 2015, “Bir Tekstil İşletmesinde Simülasyon Yardımıyla Süreç İyileştirme”, Ege Akademik Bakış Dergisi, vol. 15, no. 2, pp. 185-196.

Ertürk, H., \& Özçelik, F. 2008, "Yalın Üretim Uygulayan İşletmeler İçin Yalın Muhasebe", Uludağ Üniversitesi iktisadi ve Idari Bilimler Fakültesi Dergisi, vol. 25, no. 1, pp. 15-45.

Gaga, O. 2009, "Süreç Analizi ve Süreç İyileştirme Metodolojisi ve Kısıtlar Teorisi Yöntemiyle Süreç Analizi Uygulaması”, Yayımlanmış Yüksek Lisans Tezi, Yıldız Teknik Üniversitesi, Fen Bilimleri Enstitüsü, İstanbul.

Güler, E. 2010, “Değişim Mühendisliği Uygulamalarına Öngörü Sağlamada Simülasyon Tekniğinin Kullanımı”, Celal Bayar Üniversitesi Sosyal Bilimler Enstitüsü Dergisi, vol. 8, no. 1, pp. 147-168.

İnce, A.R., Erol, Y. \& Karagöz, N. 2013, "Bir Süreç İyileştirme Örneği Olarak Görüntülü Arşivleme ve İletişim Sisteminin (PACS) Değerlendirilmesi: Sivas Numune Hastanesi Uygulaması”, İ̧̧letme Araştırmaları Dergisi, vol. 5, no. 3, pp. $243-257$.

Nguyen, D. 2015. “A New Application Model of Lean Management In Small And Medium Sized Enterprises", International Journal of Simulation Modelling, vol. 14 no. 2, pp. 289-298.

Özçelik, F. 2013, "Yalın Performans Ölçümleri ve Yalın Üretim Uygulayan İşletmelerin Muhasebe Bölümlerinde Bir Araştırma”, International Journal of Economic and Administrative Studies, vol. 5, no. 10, ISSN: 1307-9832.

Şenel, Ş.E. 2004, "Sağlık Kuruluşlarında Süreç Yönetiminin Uygulanabilirliği ve Bir Uygulama Örneği”, Yayımlanmış Yüksek Lisans Tezi, Uludağ Üniversitesi, Sosyal Bilimler Enstitüsü, Bursa.

TDK, $2016 \quad$ http://www.tdk.gov.tr/index.php?option=com_gts\&arama=gts\&guid=TDK.GTS.571b57f856c1b6.75374539 Erişim Tarihi: 21.04.2016

Trkman, P. 2010, "The Critical Success Factors of Business Process Management", International Journal of Information Management, vol. 30, pp. $125-134$.

Yılmazer, A. \& Sarıaltın, H. 2011, "KOBi’lerde Süreç Yönetimi Uygulamalarının İncelenmesi: Sakarya illi I. Organize Sanayi Bölgesi Örneği”, Uludağ Üniversitesi, iktisadi ve Idari Bilimler Fakültesi Dergisi, vol. 30, no. 2, pp.155-186.

Zheltonogov, V., Wood, J.K., Schume, P., Borgenstrad, M., Bharade, N. \& Arsanjani, A. 2015, "Business Process Management Design Guide: Using IBM Business Process Manager", IBM Redbooks, ISBN: 978-0-7384-4059-0 